\title{
Malignant Hyperthermia: The Spontaneous Development of the MH-PSS Syndrome
}

\author{
Charles H Williams $^{1}$ \\ ${ }^{1} \mathrm{PhD}$, The Williams Research Laboratory, 100 Winterset Ct, Sunrise \\ Beach, MO 65079, United States.
}

Correspondence: Charles H Williams, Chwilliams2135@gmail.com.

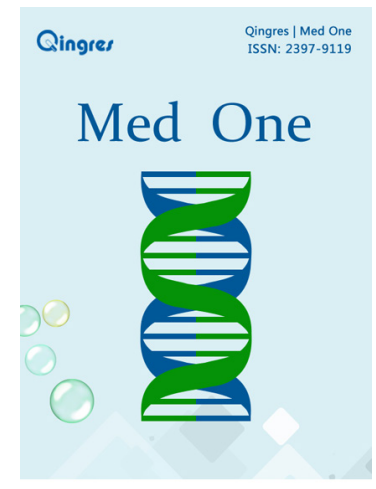

http://mo.qingres.com

\section{GOPEN ACCESS}

DOI: $10.20900 / \mathrm{mo} .20170030$

Received: October 10, 2017

Accepted: December 22, 2017

Published: December 25, 2017

Copyright: $\odot 2017$ Cain et al. This is an open access article distributed under the terms of the Creative Commons Attribution License,which permits unrestricted use, distribution, and reproduction in any medium, provided the original author and source are credited.

\begin{abstract}
Mating $\mathrm{MH}$ positive pigs to $\mathrm{MH}$ positive pigs produces an $\mathrm{F} 1$ generation that is highly stress susceptible. Recording the MUP shows $\mathrm{MH}+$ pigs have a higher $u$ voltage than control pigs. Older $\mathrm{MH}+$ pigs have an even higher $u$ voltage than control pigs. The duration of the voltage spike is also increased in $\mathrm{MH}+$ versus control pigs, and older $\mathrm{MH}+$ pigs have even a longer duration of the voltage spike. It is assumed that by concentrating the $\mathrm{MH}$ genetic defect in the $\mathrm{F} 1$ generation that the population of defective sodium channels in the acetylcholine receptor was present at a high concentration. Since the acetylcholine receptors are spatially located under the footpiece of the myoneural junction which makes them a bank of receptors that are readily accessible when acetylcholine is released by the nerve, and the action of acetylcholine is very rapid. Therefore, the electromyographic data reflects the genetically defective sodium channels as the major functional component when the data were recorded. The sodium channels can be likened to a low voltage switch in a telephone circuit that is used to route telephone calls. It suggests that the sodium channel at the acetyl choline receptor have been adapted to produce heat as well as muscle contraction and that the ability to produce copious amounts of heat is the biological mechanism that differentiates warm blooded animals from cold blooded animals.
\end{abstract}

Keywords: Malignant Hyperthermia; MH-PSS Syndrome; Stress susceptible; MH positive pigs; Sodium channels; Biological mechanism

\section{INTRODUCTION}

The lethality of $\mathrm{MH}$ is directly related to the flow of $\mathrm{Na}+$ ions thru the sodium channels in sufficient quantity to destroy the $-90 \mathrm{mv}$ charge at the cell membrane, thereby overwhelming the cells $\mathrm{Na}+, \mathrm{K}+$ ATPase 
capacity to pump $\mathrm{Na}+$ out of the muscle cell which subsequently results in muscle cell death. The death of the muscle cells from the rapid production of large quantities of heat and acids denatures the cell proteins which thereby become non functional. The acids and heat are picked up by the circulatory system, distributed to other parts of the body, and result in further damage to organs and other tissues which leads to the death of the whole organism.

The sodium channel futile cycle was developed with the rationale presented in very brief detail ${ }^{[1]}$. The other two studies provided additional details about the rationale and how sevoflurane decreased the incidence of $\mathrm{MH}$ in Kansas City and how Organon 9426 could actually prevent the development of $\mathrm{MH}^{[2,3]}$. This present article expands the concept and provides rationale for the biological function of the sodium channel heat generating cycle i.e. futile cycle.

The spontaneous development of the $\mathrm{MH}$ PSS syndrome can occur at any time in genetically selected susceptible pigs. Many times, the MH-PSS syndrome imitates at the farm or during transport where accurate recordings are not available. The net result is a dead pig from unknown causes.

It is fortunate in being able to record full blown $\mathrm{MH}-\mathrm{PSS}$ syndrome responses under controlled and recordable conditions in our previous studies ${ }^{[4]}$. Those resuts are re-presented in this present article for ease of comparison (Fig. 1), with copyright permissiom of BMJ.

These results indicate that the metabolic rate increased to over $10 x$ normal with an intense peripheral vasoconstriction that shuts down heat loss via radiation which returns when the pig dies and the hot body is radiating heat at a high level.

In addition, narrative accounts of the MH-PSS syndrome under field conditions are presented. The simplest way to increase MUP voltage is to lengthen the time the sodium channel is open. That is exactly what has happened in the adult prigs from the breeding colony. There may also be an increased flow of sodium ions thru the sodium channel when it is open.
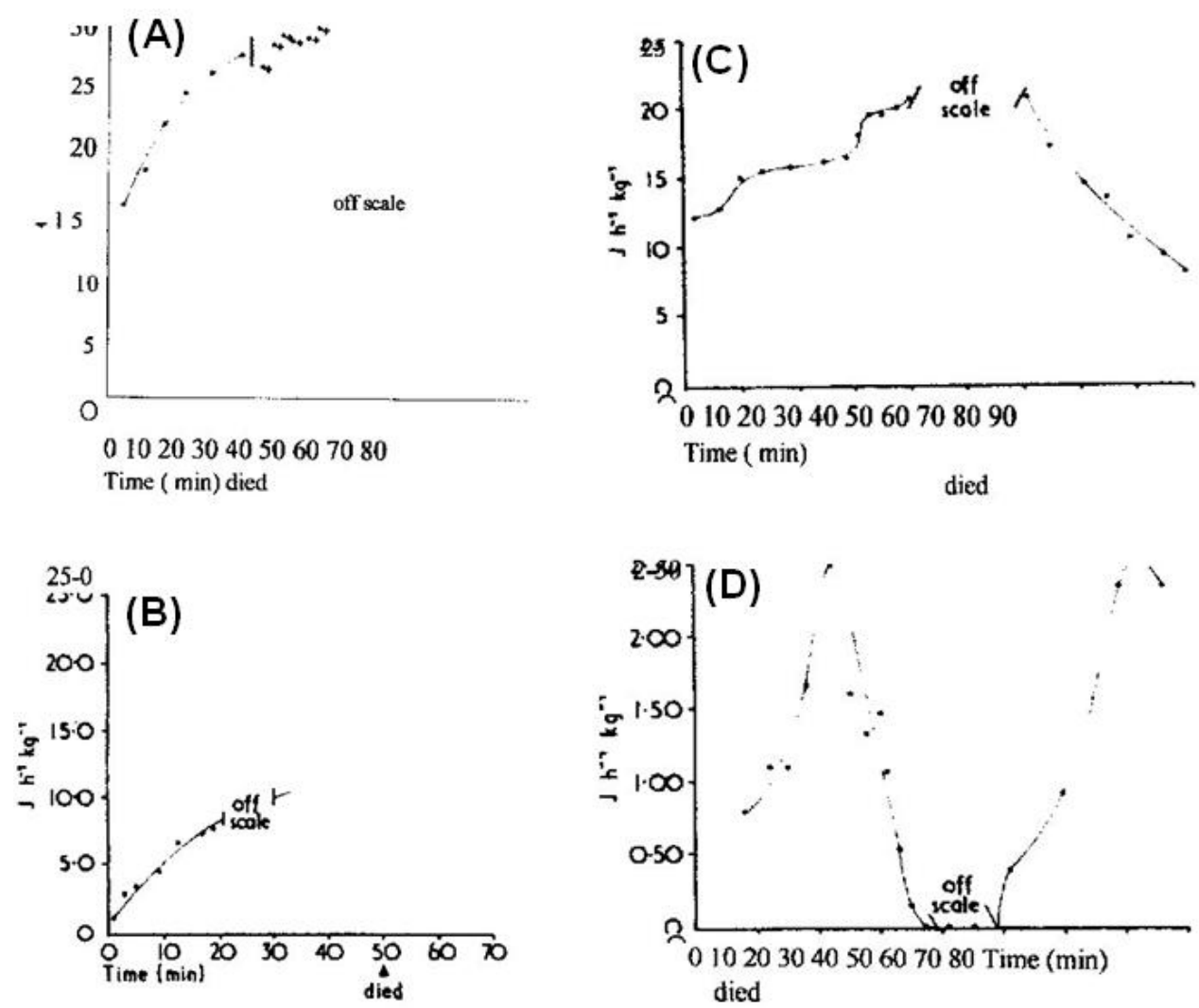

Fig. 1 Full blown MH-PSS syndrome responses under controlled and recordable conditions. (A) Total heat production recorded for P-7-1. "Off scale" $(0+)$ indicates value exceeding range of recorders. (B) Heat losses by convection (P-7-1). (C) Total heat production recorded for P-7-1 "Off scale indicates value exceeding range of recorders. (D) Radiation heat losses for P-7-1. Reproduced from Williams $\mathrm{CH}$, Houchins $\mathrm{C}$, and Shanklin $\mathrm{MD}^{[4]}$, with copyright permission of BMJ. 


\section{NARRATIVE ACCOUNTS}

During the collection of calorimeter data in the Missouri Partitional Calorimeter. The susceptible pigs were transported from Sinclair Farm to Building $\mathrm{T}-13$ in wood transport crates. The distance of travel was about 5 miles.

The first pig was loaded into the calorimeter and started recording data. In a few minutes, the pig developed MH_PSS and subsequently died in the calorimeter. The experimental results are published in $\mathrm{BMJ}^{[4]}$.

The key data are reprinted here to illustrate rapid onset and rampant acceleration of the metabolic rate and heat output.

While the calorimeter was running, I went back out to the holding area to check on the other pigs which were awaiting their turn for the calorimeter run.

A white pig was basically in difficulty as I could hear the labored breathing and see the agitation experienced by the animal. I gently let the pig out of the transport crate. The pig circled around on the concrete floor 2 or 3 times then laid down and died. The white skin color had a purple mottled appearance that indicated the effect of an intense peripheral vasoconstriction.

Another pig, a large breeding boar died on a hot (105Fo) day in the swine barn facility. All of these animals were posted by Loren Kintner, DVM who diagnosed the deaths due to MH-PSS.

\section{METHODS AND MATERIALS}

The pigs used in these experiments were raised from the initial five pigs reserved as breeding stock at Arlington Farms, UW during January 1969. They were challenged with $3 \%$ Halothane in $\mathrm{O} 2$ and identified as $\mathrm{MH}$ susceptible whenever the rear legs became extended and appeared to be in rigor. The Halothane challenge was discontinued and the animals spontaneously recovered and were used for breeding stock. The two males and three females were raised in Swine Barn A under Leo's supervision. Unfortunately, when they reached 225$240 \mathrm{lbs}$. in weight, they were hauled off to the UW slaughter house. Leo found them missing and called the slaughter house and recovered one male and two females that had not been slaughtered. The MH breeding animals were moved to the UW Sheep Farm so there could not be any other possible confusion with other pigs in Swine Barn A. The key
MHS breeding animals were moved to Sinclair Farm at $U$ of $M O$ in 1973 when I relocated to the University of Missouri for a new research position. Later in 1982, the entire stock of MH susceptible breeding animals was moved to TTUHSC at EI Paso, TX. They were located on a pig farm near to El Paso, TX.

The Halothane challenge test was found to be very useful in identifying $\mathrm{MH}$ susceptible pigs for breeding and experimental work. Mating MHS + males with $\mathrm{MHS}+$ females produced $\mathrm{MHS}++\mathrm{F} 1$ pigs that were highly susceptible to the MH-PSS genetic syndrome. The defective sodium channels at the myoneural junction are present at a high population level. The MH genetic defect is not sex linked so the reverse mating program produces highly susceptible pigs. Therefore, the electromyographic data reflects the genetically defective sodium channels as the major functional component when the data were recorded.

It is believed that MH-PSS susceptibility is directly related to a higher MUP voltage and duration in the older animals. The data from our previous publication is presented in graphical format for easier evaluation and comparison (Fig. 2 and Fig. 3).

Duration of the voltage spike represents the length of time the sodium channel is open to allow sodium ions to pass through and create the voltage spike. The data suggests that the age of the animals plays a role in the duration of the spike. This observation is consistent with actual susceptibility to the MH-PSS syndrome whenever pigs are stressed by hauling to market. The Organon 9426 data indicated a reduction in the actual number of functional sodium channels in MHS versus normal pigs ${ }^{[2]}$. Thus, aging makes the pigs more susceptible to develop the MH-PSS syndrome.

James R Stewart, an ATT Special Services telephone repairman ${ }^{[6]}$ likens the sodium channel to a switch in a low voltage circuit that is used to route telephone calls. The sodium channels are spatially located under the foot piece of the motor nerve where they can act as bank of switches to regulate muscle function.

Further, It suggests that the sodium channel futile cycle may be the most likely the biological mechanism used by warm blooded animals to maintain core temperatures at the appropriate level of 37-38 degrees $\mathrm{C}$. Basal metabolic rates may not be sufficient to maintain an elevated core body temperature. The prime example of that result would be cold blooded animals that must seek a warm environment in order to raise body temperature up to 
$P<0.05 \quad$ MUP Characteristics in Muscle

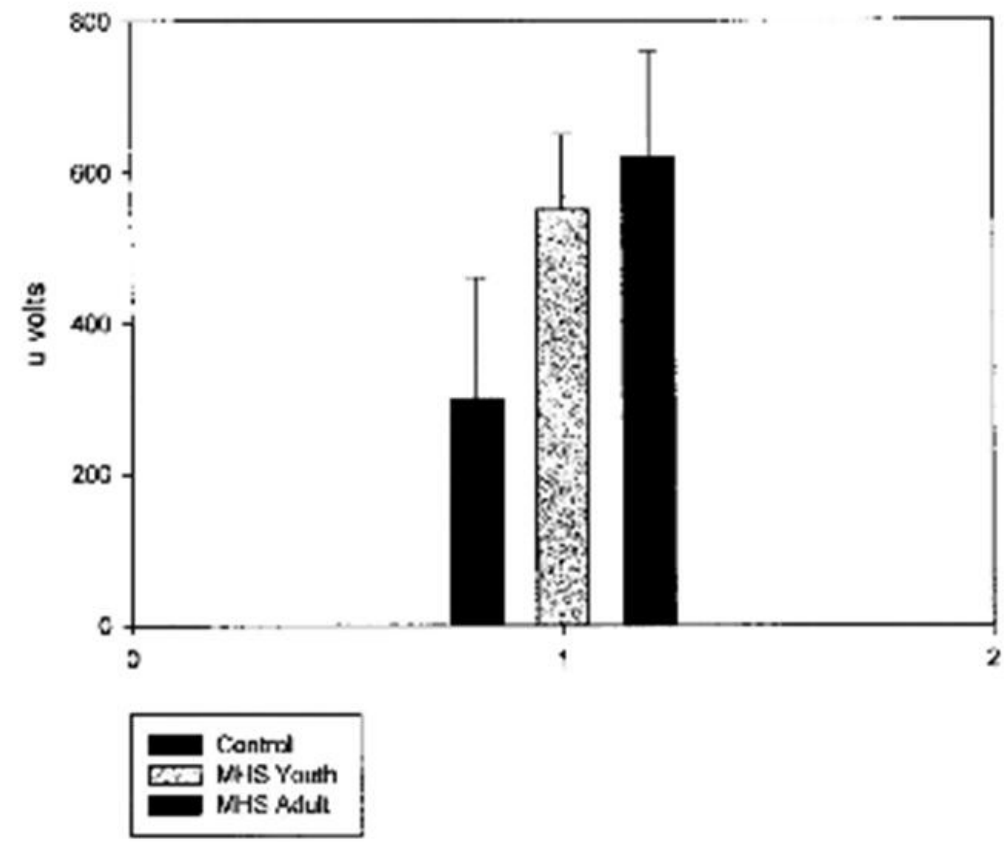

Fig. 2 Micro volts from MUP recordings of control, MHS Youth, MHS Adult pigs. Graphs plotted by Sigma Plot v11, from data in tabular format in Steiss, Bowen, and Williams ${ }^{[5]}$

\section{P<0.05 MUP Characteristics in Muscle}

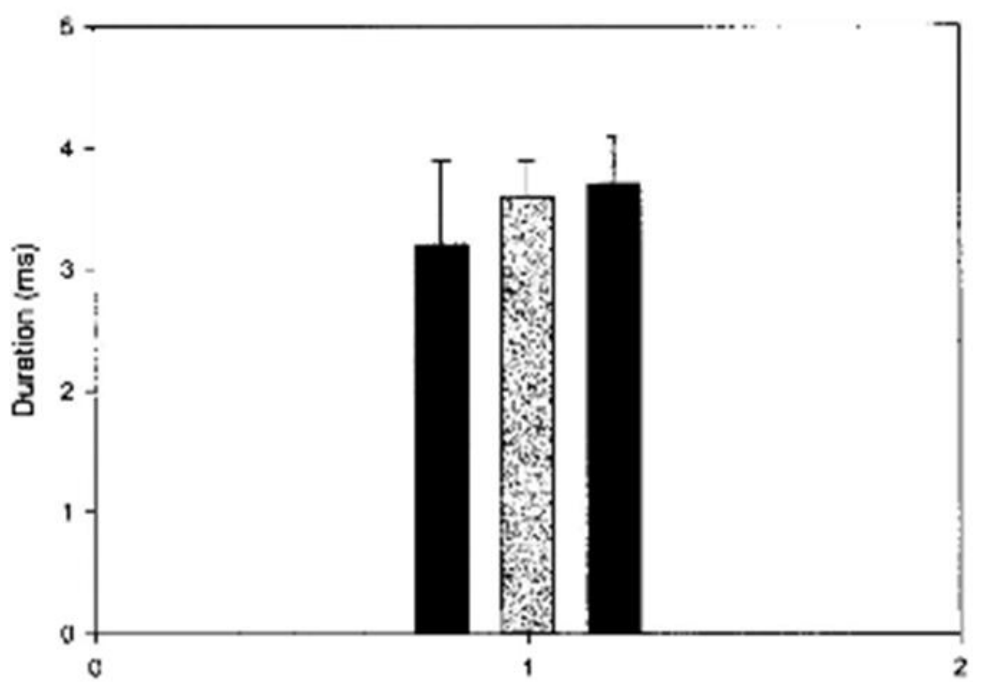

$$
\begin{aligned}
& \text { Contres } \\
& \text { MiHS Youtt } \\
& \text { MHS Adult }
\end{aligned}
$$

Fig. 3 Duration in millisecs of the MUP voltages recorded in control, MHS Youth, MHS Adult pigs. Graphs plotted by Sigma Plot v11, from data in tabular format in Steiss, Bowen, and Williams ${ }^{[5]}$ 
a functional level.

The ability to control the mating in the pig colony allowed one to routinely produce homozygous F1 offspring ${ }^{[7-9]}$. This provides one with very susceptible animals that exhibited the $\mathrm{MH}$ syndrome at maximal sensitivity.

Please note that the older $\mathrm{MH}$ susceptible pigs continued to exhibit an increased voltage spike and a longer duration before the sodium channels finally closed. It is believed that this increased voltage for a longer duration is the manifestation of genetically defective sodium channels. A $30 \%$ decrease in the actual number of sodium channels may be the result of a biological correction to enable the animal to survive with the $\mathrm{MH}$ syndrome genetic defect ${ }^{[2]}$.

\section{REFERENCES}

1. Williams $\mathrm{CH}$. Malignant hyperthermia: A runaway thermogenic futile cycle at the sodium channel level. Adv Biosci Biotechnol. 2014; 05: 197-200.

2. Williams $\mathrm{CH}$. Malignant Hyperthermia: Evaluation of "Organon" 9426 in Malignant Hyperthermia Susceptible Pigs. Open J Mol Integr Physiol. 2015; 05: 29-36.

3. Williams $\mathrm{CH}$. Hoech GP, Zukaitis MG. A Review of the Factors Affecting the Incidence of Malignant Hyperthermia in the Greater Kansas City Area. Adv Biosci Biotechnol. 2014; 05: 452461.

4. Williams $\mathrm{CH}$, Houchins $\mathrm{C}$, Shanklin MD. Energy Metabolsim in pigs susceptible to the fulminant hyperthermia-stress syndrome. BMJ. 1975; 3 : 411-413.

5. Steiss JE, Bowen JM, Williams CH. Electromyographic evaluation of malignant hyperthermia-susceptible pigs. Am J Vet Res. 1981; 42(7): 1173-1176.

6. Stewart JR. Personal communication. 2015-

\section{CONCLUSION}

Mating $\mathrm{MH}$ positive pigs to $\mathrm{MH}$ positive pigs produces an F1 generation that is highly stress susceptible. The studies based on this model reveal that the electromyographic data reflects the genetically defective sodium channels as the major functional component when the data were recorded. The sodium channels can be likened to a low voltage switch in a telephone circuit that is used to route telephone calls. It suggests that the sodium channel at the acetyl choline receptor have been adapted to produce heat as well as muscle contraction and that the ability to produce copious amounts of heat is the biological mechanism that differentiates warm blooded animals from cold blooded animals.

2017.

7. Williams $\mathrm{CH}$, Lasley JF. The mode of inheritance of the fulminant hyperthermia-porcine stress syndrome in swine. In: Proceedings of the Focus on Malignant Hyperthermia Symposium, Wausau, Wisconsin , 13 September 1974, edited by E O Henschel, New York: Appleton Century Crofts. 1977; pp. 141-148.

8. Williams $\mathrm{CH}$, Shanklin $\mathrm{M}$, Hedrick $\mathrm{H}$, Muhrer M, Stubbs D, Krause G, Payne C, Benedict $J$, Hutchinson D, Lasey J. The fulminant hyperthermia-stress syndrome - Genetic aspects, hemodynamic and metabolic measurements in susceptible and normal pigs. Second International Symposium on Malignant Hyperthermia. 1-3 April 1977 at Denver, edited by AJ Aldrete and BA Britt, New York: Grune and Stratton. 1978; pp113-140.

9. Williams $\mathrm{CH}$. Some observations on the etiology of the fulminant hyperthermia-stress syndrome. Perspect Biol Med.1976; 20(1): 120-130. 